\title{
Conhecer as emoções: a aplicação e avaliação de um programa de intervenção
}

\author{
Carla Pereira \\ Secretaria Regional da Educação e Recursos Humanos \\ Luísa Soares \\ Universidade da Madeira \\ Diana Alves \\ Orlanda Cruz \\ Universidade do Porto \\ Mónica Fernandez
}

Resumo

Procura-se explorar a importância do conhecimento emocional, através da avaliação de um Programa de Desenvolvimento do Conhecimento Emocional, a partir de um design experimental de pré e pós-teste. Participaram 25 crianças de educação pré-escolar entre cinco e seis anos e foi utilizada a Escala de Avaliação do Conhecimento Emocional (EACE), que permite obter uma nota total da Percepção Emocional Correta (PEC) e foi utilizada em pré e pós-teste. Os resultados evidenciam um aumento significativo do conhecimento emocional entre o pré-teste e o pós-teste, ocorrendo os progressos mais significativos nas dimensões comportamentos emocionais e situações emocionais.

Palavras-chave: emoções; desenvolvimento psicológico; crianças.

\begin{abstract}
Emotions: The implementation and evaluation of an intervention program. The present research highlights the importance of emotional knowledge through the evaluation of the effectiveness of a program, with experimental design of pre and post-test. 25 children-participants attended a pre-school class, aged from five and six years old. It was used the Assessment of Children's Emotion Skills Questionnaire for the Portuguese context, which gives a total score for the Correct Emotional Perception. The results show a significant increase in emotional knowledge between the pre-test and post-test, more significant progress in the dimensions of emotional behaviors and emotional situations.
\end{abstract}

Keywords: emotions; psychological development; children.

\section{Resumen}

Conocé las emociones: La implementación y evaluación de un programa de intervención. La presente investigación pone de relieve la importancia del conocimiento emocional a través de la evaluación de la efectividad de un programa, con un diseño experimental de pre y post-test. 25 niños participantes, con edades comprendidas entre cinco y seis años de edad, asistieron a una clase de preescolar. Se utilizó el Cuestionario de Evaluación de Habilidades Emocionales para la Infancia para el contexto portugués, lo que da una puntuación total de percepción emocional correcta. Los resultados muestran un incremento significativo en el conocimiento emocional entre el pre-test y pos-test, siendo el avance más significativo en las dimensiones de los comportamientos y de las situaciones emocionales.

Palabras clave: emociones; desarrollo psicológico; los niños.

oleman (1997), Mayer e Salovey (1997), Saarni, (1997), Bonhert, Crnic e Lim (2003) referem a competência emocional como a capacidade dos indivíduos expressarem emoções adequadas aos acontecimentos, de modo a adequar as suas reações emocionais negativas e compreender o significado dos estados/expressões emocionais para o self e para os outros. É composta por três dimensões: expressão emocional, regulação emocional e conhecimento emocional. 
A expressão emocional assume um papel central na competência emocional, é o lado visível e partilhado das emoções, na qual a partilha de afeto positivo facilita o estabelecimento de amizades e permite à criança ser mais aceite socialmente. A investigação revela que as crianças que experimentam e expressam mais emoções positivas do que negativas, são avaliadas pelos professores como sendo mais assertivas e alegres e menos agressivas. Estas crianças comportam-se de uma forma mais pró-social face aos pares e parecem ser mais aceites (Denham, McKinley, Couchoud, \& Holt, 1990).

A regulação emocional é a capacidade adquirida no decorrer da infância que permite controlar as emoções e adequá-las aos contextos. Essas experiências, nomeadamente as brincadeiras, o interagir socialmente com os pares e o obedecer às regras dos adultos, vão condicionar o êxito pessoal e relacional (Izard, Stark, Trentacosta, \& Schultz, 2008). Este componente assume um papel vital, quando a intensidade, a duração ou qualquer outro parâmetro da experiência emocional não se adequa às expetativas, aos objetivos da criança ou aos padrões sociais (Denham et al., 2003).

O conhecimento emocional representa a capacidade de reconhecer e nomear as expressões emocionais e permite ao indivíduo identificar e compreender corretamente os sinais emocionais dos interlocutores e desta forma responder adequadamente às expetativas dos outros. Inclui o conhecimento da expressão emocional, dos comportamentos emocionais e das situações estimuladoras de emoções. O conhecimento das expressões emocionais permite que as crianças reconheçam sinais faciais de emoções discretas como alegria, tristeza, zanga e medo, bem como retenham na memória indicadores verbais associados às expressões emocionais (Izard \& Ackerman, 2004). Em suma, o conhecimento emocional permite às crianças reagirem adequadamente com os outros, determinando a qualidade das relações que estas estabelecem com os seus pares.

Um instrumento que vise a avaliação do conhecimento emocional no período escolar, terá em conta a identificação das emoções de alegria, tristeza, medo e zanga, expressos em expressões faciais, situações e comportamentos emocionais (e.g. ACES - Schultz, Izard, \& Bear, 2002 citado por Alves, Cruz, Duarte, \& Martins, 2008). Machado, Veríssimo, Santos e Rolão (2008) destacam que nas crianças em idade pré-escolar são diferenciadas as três componentes da competência emocional (acima referidas) e se encontram associadas com o ajustamento escolar.

Alves (2006) refere que a criança é um processador da informação social e este processamento depende do seu desenvolvimento cognitivo e emocional. A maneira como lê e compreende a realidade social, nomeadamente as expressões emocionais e os comportamentos sociais dos seus pares, depende da sua competência emocional e das suas capacidades cognitivas. Estas determinam a forma como a criança interpreta, organiza e integra a sua experiência de interação com os outros, definindo assim o seu funcionamento sócio-emocional. Desenvolveram-se várias investigações que destacam o papel que a competência emocional assume na competência social das crianças (Saarni, 1999). Alguns dos programas dedicados à educação sócio-emocional agrupam os objetivos gerais recorrentes em cinco categorias: 1) auto-consciência emocional (conhecimento emocional): adquirir um melhor conhecimento das próprias emoções, reconhecer as diferenças entre sentimentos e ações e compreender as causas dos sentimentos; 2) gestão das emoções (regulação emocional): desenvolver habilidades para controlar as próprias emoções, prevenir os efeitos prejudiciais das emoções negativas (por exemplo, melhorar a capacidade para expressar verbalmente a ira sem lutar), desenvolver habilidades de resistência à frustração, desenvolver habilidades para gerar emoções positivas; 3) controlar produtivamente as emoções (regulação comportamental): desenvolver habilidades de auto-motivação, maior capacidade de concentração nas tarefas e maiores responsabilidades, desenvolver a capacidade de saber esperar por recompensas a longo prazo em detrimento de recompensas imediatas; 4) empatia: desenvolver a capacidade de aceitar a perspectiva do outro, desenvolver sentimentos de empatia e sensibilidade com os outros, e desenvolver a capacidade de escuta; 5) gerir relacionamentos (competência emocional): desenvolver competências para resolver conflitos e negociar acordos, desenvolver a capacidade de cooperação, de partilha e de ajuda (Bisquerra, 2000; Goleman, 1997; Vallés \& Vallés, 2000).

As crianças que transitam para o primeiro ciclo encaram o processo como a grande entrada no mundo dos mais crescidos, um novo estatuto e oportunidade de aprender coisas novas e diferentes. Também demonstram receio, possivelmente por terem de enfrentar situações novas, mas o principal sentimento face ao primeiro ciclo parece ser de curiosidade e de expectativa. As crianças necessitam de desenvolver sentimentos de confiança em relação ao seu mundo, sendo que neste processo é essencial ter atitudes e cuidados educativos disponibilizando à criança a noção de previsibilidade do contexto. A ação educativa deve ser coerente de forma a assegurar a continuidade entre "as duas etapas iniciais da escolarização da criança" sendo esta coerência indispensável para que o processo de desenvolvimento da criança se desenrole de forma contínua e global, assegurando-se assim a qualidade das aprendizagens (Rodrigues, 2005). Assim, o objetivo deste estudo é avaliar a aplicação de um programa de desenvolvimento do conhecimento emocional.

\section{Método}

\section{Participantes}

Os participantes de ambos os grupos (experimental e controle) foram selecionados considerando dois critérios: (1) a frequência de um estabelecimento de ensino pré-escolar e (2) idade cronológica igual ou superior a 60 meses. O grupo experimental é composto por 25 crianças da sala dos cinco anos de um complexo escolar de Portugal. As crianças que integram a amostra apresentam um desenvolvimento normativo, não estando identificadas necessidades educativas especiais. Relativamente ao gênero da amostra, 11 crianças (44\%) pertencem 
ao gênero masculino e 14 (56\%) pertencem ao gênero feminino. A idade das crianças varia entre os 5,1 anos e os 6 anos, sendo a média de 5,46 anos $(D P=0,29)$.

As crianças do grupo de controlo são 23 , com idades e gênero equivalentes às do grupo experimental ( 5 - 6 anos de idade e 11 crianças de gênero masculino e 12 do gênero feminino). A este grupo de crianças, apenas foram aplicados os instrumentos de avaliação do conhecimento emocional (no pré e pós teste), utilizando o mesmo intervalo de tempo (3 meses) e não houve qualquer aplicação do programa de intervenção.

Relativamente ao nível de escolaridade dos pais, três possuem o mestrado (6\%), 31 possuem uma licenciatura $(62 \%)$, quatro possuem o bacharelato ( $8 \%$ ), um possui o curso técnico profissional (2\%) e 11 possuem o ensino secundário (12 anos de escolaridade; 22\%). O nível de escolaridade da mãe revela que duas possuem o mestrado, 20 possuem uma licenciatura, duas possuem o bacharelato e uma possui o ensino secundário (12 anos de escolaridade). O nível de escolaridade do pai revela que um possui o mestrado, 11 possuem a licenciatura, dois possuem o bacharelato, um possui o curso técnico profissional e 10 possuem o ensino secundário (12 anos de escolaridade).

\section{Instrumentos}

Questionário de Caracterização Sócio - Demográfica das Famílias. O Questionário de Caracterização Sócio-Demográfica das famílias permitiu recolher a data de nascimento da criança, o gênero e o nível de escolaridade dos pais.

Escala de Avaliação do Conhecimento Emocional. A EACE foi traduzida e adaptada por Alves, (2006) a partir do modelo ACES - Assessment of Children's Emotion Skills desenvolvido por Schultz, Izard e Bear (2002). É constituída por três dimensões: Expressões faciais, Situações emocionais e Comportamentos emocionais. As notas obtidas em cada uma destas dimensões contribuem para a nota total denominada Percepção Emocional Correta (PEC). Em cada dimensão, são apresentados itens em que as crianças têm de responder uma das cinco alternativas: contente, triste, zangada, assustada ou normal. A dimensão das Expressões Faciais é constituída por 20 itens e analisa a capacidade das crianças perceberem as expressões faciais observadas nos outros. São utilizadas 20 fotografias de crianças de idade escolar, manifestando as cinco expressões emocionais (contente, triste, zangada, assustada ou normal). A dimensão das Situações Emocionais é constituída por 15 itens e analisa a capacidade das crianças em discriminar a emoção subjacente à situação apresentada. Na dimensão dos Comportamentos Emocionais cada criança terá que, perante os 15 itens, identificar como é que a criança protagonista se está a sentir.

Para cada uma das três dimensões, é calculado o total de respostas corretas. Obtemos ainda uma nota total da PEC, que reflete o número de vezes que cada criança respondeu corretamente, ao longo das três dimensões, aos itens relacionados com a alegria, tristeza, zanga, medo e normal. Tal como referido por Mostow, Izard, Fine e Trentacosta (2002), o cálculo do PEC, implicou a padronização prévia do total de respostas corretas apresentadas em cada uma das escalas para os itens relativos à alegria, tristeza, zanga, medo e normal.

Programa de Desenvolvimento do Conhecimento Emocional. O programa prevê 12 sessões, nas quais são dinamizadas atividades de promoção do desenvolvimento do conhecimento emocional. Está dividido em dois campos de ação: (1) Conhecer o meu corpo, com seis sessões dirigidas ao conhecimento do próprio corpo e (2) Conhecer as emoções, com seis sessões orientadas para o desenvolvimento do conhecimento emocional. Obedece a uma ordem de aprendizagem das emoções do geral para o particular e de fora para dentro. As emoções são apresentadas com atividades semelhantes/homogêneas, de modo a evitar dinâmicas/impactos mais fortes do que outras (de modo a evitar que umas atividades sejam mais motivadoras/interessantes do que outras; as atividades seguiram a mesma linha de pensamento), evitando que isso influencie a assimilação do conhecimento de cada emoção em particular como também as emoções no seu todo. Inicialmente são dinamizadas as sessões da consecução do esquema corporal, da consciência do próprio corpo e das características específicas e particulares de cada criança. Depois é feita a transição do corpo físico para o corpo emocional, do conhecimento do mundo com o corpo e com o que sentimos no coração. São exploradas situações que abordam momentos de bem-estar emocional e de sentimentos positivos pelo outro. Depois dão-se a conhecer as quatro emoções básicas, promovendo o conhecimento e a tomada de consciência emocional.

Este programa destina-se a crianças em idade pré-escolar (pode ser aplicado em infantários, jardins de infância e escolas do ensino básico com pré-escolar). A duração está prevista para 12 semanas (três meses), com uma periodicidade semanal. Cada sessão dura aproximadamente uma hora. A seleção dos domínios de ação e das atividades baseou-se por um lado nas orientações curriculares para a educação pré-escolar e por outro no desenvolvimento emocional da criança em idade pré -escolar.

A organização das sessões enquadra-se na perspectiva da psicologia do desenvolvimento, em que a criança aprende do todo para o particular e de fora para dentro (teorias do desenvolvimento de Piaget, Erikson, Winnicott e as Orientações Curriculares para a Educação Pré-Escolar) bem como na perspectiva de aquisição de competências emocionais defendida por Mayer e Salovey (1997), em que os níveis de competência se adquirem, em termos de complexidade e desenvolvimento, de acordo com a seguinte ordem: percepção e expressão das emoções, assimilação das emoções, compreensão e análise de emoções e gestão das emoções. Assim, o desenrolar das sessões obedece a uma abordagem das emoções básicas e de como as sentir e vivenciar dentro e fora do corpo.

A aplicação das sessões do programa decorreu no contexto de escola, dentro da sala de atividades e em conjunto com todas as crianças. As atividades são apresentadas em diferentes suportes. Incluíram a manipulação de diversos materiais lúdicos de modo a captar e manter a atenção da criança. A exposição das sessões é efetivada com motivação em grande grupo e depois com um trabalho individual de consolidação do 
conhecimento transmitido. As atividades do programa foram associadas às atividades do projeto curricular de turma.

\section{Procedimento}

Num primeiro momento, foi solicitada e conseguida a autorização da direção para realizar o estudo. Num segundo momento, foi pedida autorização aos Encarregados de Educação. Este procedimento permitiu-nos identificar por escrito as crianças não autorizadas a participar. Este pedido também foi realizado presencialmente na reunião anual dos encarregados de educação da sala onde a investigação foi realizada. Recolheram-se os dados necessários ao Questionário de caracterização sociodemográfica das famílias e iniciou-se o processo de aplicação da EACE como pré-teste. A aplicação da EACE foi feita de forma individual num local sossegado do complexo escolar. Posteriormente a esta avaliação pré-teste, aplicou-se o Programa de Desenvolvimento do Conhecimento Emocional, elaborado por Pereira e Soares (2011) durante os meses de dezembro de 2010, janeiro e fevereiro de 2011. No mês de março de 2011, foi aplicado novamente a EACE como pós-teste nas mesmas condições logísticas.

\section{Resultados}

A Tabela 1 apresenta uma análise descritiva das médias e os desvios-padrão obtidos no pré e no pós-teste, bem como em nível do gênero das crianças. Verificou-se que a diferença não é estatisticamente significativa entre os gêneros nos dois momentos de avaliação (média pré-teste 28,4; média pós-teste 36,$4 ; p>0,504)$. Os resultados apontam que, para a amostra do gênero feminino, a pontuação média obtida antes da intervenção foi de 28,5 contra 28,3, observada no gênero masculino (ver Tabela 1). Esta proximidade de valores esclarece quanto ao valor-p resultante da comparação entre estas duas amostras. Assim sendo, não se observam diferenças significativas entre as crianças de ambos os gêneros no momento pré-teste.

\section{Tabela 1}

Médias e Desvios- padrões Segundo o Gênero das Crianças (Pré e PósTeste)

\begin{tabular}{|c|c|c|c|c|c|c|c|c|}
\hline & \multicolumn{4}{|c|}{ Gênero } & \multirow{2}{*}{\multicolumn{2}{|c|}{ Total }} & \multirow{2}{*}{\multicolumn{2}{|c|}{$\begin{array}{c}\text { Teste } \\
t \text {-Student }\end{array}$}} \\
\hline & \multicolumn{2}{|c|}{$\begin{array}{c}\text { Feminino } \\
(n=14)\end{array}$} & \multicolumn{2}{|c|}{$\begin{array}{c}\text { Masculino } \\
(n=11)\end{array}$} & & & & \\
\hline & $M$ & $D P$ & $M$ & $D P$ & $M$ & $D P$ & $t$ & Sig. \\
\hline $\begin{array}{l}\text { Perceção Emo- } \\
\text { cional Correta } \\
\text { (TOTAL) Pré }\end{array}$ & 28,5 & 3,7 & 28,3 & 3,8 & 28,4 & 3,7 & 0,151 & 0,881 \\
\hline $\begin{array}{l}\text { Perceção Emo- } \\
\text { cional Correta } \\
\text { (TOTAL) Pós }\end{array}$ & 36,7 & 3,1 & 35,9 & 2,7 & 36,4 & 2,9 & 0,678 & 0,504 \\
\hline
\end{tabular}

A Figura 1 ilustra a evolução observada no grupo após a intervenção. Inicialmente, $50 \%$ do grupo pontuou abaixo de 30 e após a intervenção, todas as crianças apresentaram resultados acima deste valor. As duas crianças que apresentaram valores muito mais baixos no pré-teste passaram para valores superiores ou iguais a 30 no pós-teste. No pré-teste, a pontuação máxima foi de 34 e no pós-teste foi de 44 . Após a intervenção, apenas $25 \%$ das crianças apresentaram resultados abaixo dos 30 .

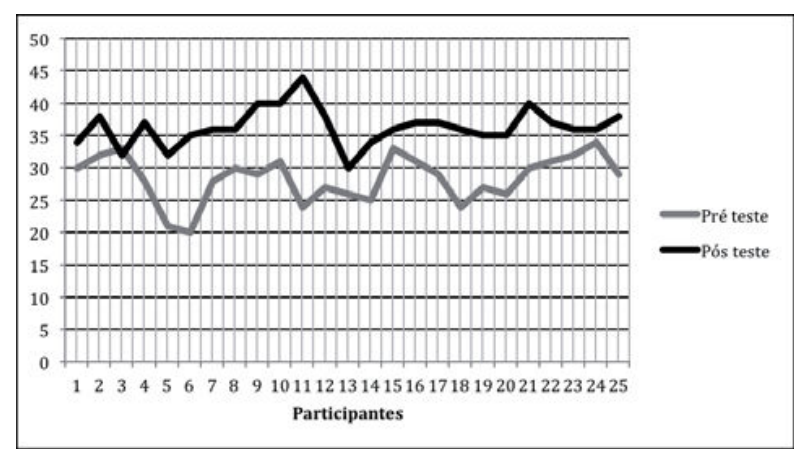

Figura 1. Resultados Individuais do PEC no Pré e Pós-teste

Após a intervenção, a média obtida pelo gênero feminino foi de 36,7 contra 35,9 observada no gênero masculino; à semelhança do observado anteriormente, não existem diferenças significativas entre estes dois grupos na avaliação posterior à intervenção (ver Tabela 1). Podemos afirmar que antes da intervenção, os dois grupos não diferem significativamente entre si e como essa semelhança se manteve após a intervenção, conclui-se que o programa poderá eventualmente ter contribuído para alguma melhoria do conhecimento emocional, quer para o gênero masculino, quer para o gênero feminino, apesar de as diferenças não serem estatisticamente significativas.

Quando comparamos grupo experimental e grupo de controle (ver Tabela 2: Resultados das Médias e Desvios-padrão entre grupo experimental e grupo de controle no pré-teste) os resultados revelam que os valores de prova observados no teste de hipótese foram superiores a 0,05 , pelo que não há evidência de diferenças significativas entre grupo experimental e grupo de controle antes da realização do programa (grupo pré). A Tabela 2 expõe a média com desvio-padrão e IC a $95 \%$ obtidos no grupo controle e experimental. Como é visível, em todas as componentes não foram observadas diferenças significativas, pois o valor $p$ é superior a 0,05. 
Tabela 2

Resultados das Médias e Desvios-padrões entre o Grupo Experimental e Grupo de Controle no Pré-Teste

\begin{tabular}{|c|c|c|c|c|c|c|}
\hline & Grupo & $N$ & $\bar{x} \pm S$ & IC $95 \%$ & U & $\begin{array}{c}\text { Valor } \\
p\end{array}$ \\
\hline \multirow{2}{*}{$\begin{array}{l}\text { Comportamentos } \\
\text { - Percepção Emocio- } \\
\text { nal Correta }\end{array}$} & Experimental & 25 & $6,7 \pm 1,5$ & $(6,1 ; 7,3)$ & \multirow[b]{2}{*}{201,000} & \multirow[b]{2}{*}{0,067} \\
\hline & Controle & 23 & $7,7 \pm 1,7$ & $(7,0 ; 8,4)$ & & \\
\hline \multirow{2}{*}{$\begin{array}{l}\text { Situações - Per- } \\
\text { cepção Emocional } \\
\text { Correta }\end{array}$} & Experimental & 25 & $6,9 \pm 1,7$ & $(6,3$ & \multirow[b]{2}{*}{227,500} & \multirow[b]{2}{*}{0,204} \\
\hline & Controle & 23 & $7,7 \pm 1,5$ & $(7,1 ; 8,3)$ & & \\
\hline \multirow{2}{*}{$\begin{array}{l}\text { Expressões faciais } \\
\text { - Percepção Emocio- } \\
\text { nal Correta }\end{array}$} & Experimental & 25 & $14,8 \pm 1,8$ & $(14,1 ; 15,5)$ & \multirow[b]{2}{*}{280,000} & \multirow[b]{2}{*}{0,875} \\
\hline & Controle & 23 & $15,0 \pm 2,1$ & $(14,2 ; 15,8)$ & & \\
\hline $\begin{array}{l}\text { Percepção Emocio- } \\
\text { nal Correta (TOTAL) }\end{array}$ & Experimental & 25 & $28,4 \pm 3,7$ & $(27,0 ; 29,8)$ & 205,500 & 0,089 \\
\hline
\end{tabular}

$\mathrm{Na}$ Tabela 3, que apresenta os resultados das médias e desvio-padrão entre o grupo experimental e grupo de controle no pós teste, ou seja, após a aplicação do programa, observa-se que existem diferenças significativas entre os dois grupos em todas as dimensões $(p<0,05)$. Deste modo, esta variação parece ter sido provocada pelo programa e não por uma evolução natural das crianças, uma vez que no grupo experimental, no qual foi aplicado o programa de intervenção, as diferenças de resultados são significativamente diferentes.

\section{Tabela 3}

Resultados das Médias e Desvios- padrões entre o Grupo Experimental e Grupo de Controle no Pós-Teste

\begin{tabular}{lcccccc}
\hline & Grupo & $\boldsymbol{N}$ & $\bar{x} \pm S$ & IC 95\% & $t$ & Valor $\boldsymbol{p}$ \\
\hline Comportamentos - & Experimental & 25 & $9,2 \pm 1,7$ & $(8,5 ; 9,9)$ & & \\
$\begin{array}{l}\text { Percepção Emocional } \\
\text { Correta }\end{array}$ & Controle & 23 & $7,7 \pm 1,4$ & $(7,1 ; 8,2)$ & 3,356 & 0,002 \\
Situações - Percepção & Experimental & 25 & $9,8 \pm 1,7$ & $(9,1 ; 10,4)$ & & \\
Emocional Correta & Controle & 23 & $7,7 \pm 1,4$ & $(7,2 ; 8,3)$ & 4,463 & 0,000 \\
Expressões faciais - & Experimental & 25 & $17,4 \pm 1,2$ & $(16,9 ; 17,9)$ & & \\
$\begin{array}{l}\text { Percepção Emocional } \\
\text { Correta }\end{array}$ & Controle & 23 & $15,1 \pm 2,1$ & $(14,2 ; 15,9)$ & 4,663 & 0,000 \\
$\begin{array}{l}\text { Percepção Emocional } \\
\text { Correta (TOTAL) }\end{array}$ & Experimental & 25 & $36,4 \pm 2,9$ & $(35,2 ; 37,5)$ & & \\
\hline
\end{tabular}

Tabela 4

Resultados PEC Pré e Pós-Teste entre o Grupo Experimental e Grupo de Controle

\begin{tabular}{|c|c|c|c|c|c|c|}
\hline Grupo & & $n$ & $\bar{x} \pm S$ & $95 \%$ & $t$ & $\begin{array}{c}p- \\
\text { value }\end{array}$ \\
\hline \multirow{12}{*}{ Experimental } & Comp_PEC_préa & 25 & $6,7 \pm 1,5$ & $(6,1 ; 7,3)$ & \multirow{2}{*}{$-5,775$} & \multirow{2}{*}{0,000} \\
\hline & Comp_PEC_Pós & 25 & $9,2 \pm 1,7$ & $(8,5 ; 9,9)$ & & \\
\hline & Situações_PEC_Préb & 25 & $6,9 \pm 1,7$ & $(6,3 ; 7,6)$ & \multirow{2}{*}{$-6,652$} & \multirow{2}{*}{0,000} \\
\hline & Situações_PEC_Pós & 25 & $9,8 \pm 1,7$ & $(9,1 ; 10,4)$ & & \\
\hline & EXP_PEC_Préc & 25 & $14,8 \pm 1,8$ & $(14,1 ; 15,5)$ & \multirow{2}{*}{$-5,863$} & \multirow{2}{*}{0,000} \\
\hline & EXP_PEC_Pós & 25 & $17,4 \pm 1,2$ & $(16,9 ; 17,9)$ & & \\
\hline & PEC (TOTAL) Préd & 25 & $28,4 \pm 3,7$ & $(27,0 ; 29,8)$ & \multirow{2}{*}{$-9,182$} & \multirow{2}{*}{0,000} \\
\hline & PEC (TOTAL)_Pós & 25 & $36,4 \pm 2,9$ & $(35,2 ; 37,5)$ & & \\
\hline & Comp_PEC_Pré & 23 & $7,7 \pm 1,7$ & $(7,0 ; 8,4)$ & \multirow{2}{*}{0,113} & \multirow{2}{*}{0,911} \\
\hline & Comp_PEC_Póse & 23 & $7,7 \pm 1,4$ & $(7,1 ; 8,2)$ & & \\
\hline & Situações_PEC_Pré & 23 & $7,7 \pm 1,5$ & $(7,1 ; 8,3)$ & \multirow{2}{*}{0,000} & \multirow{2}{*}{1,000} \\
\hline & Situações_PEC_Pós ${ }^{\dagger}$ & 23 & $7,7 \pm 1,4$ & $(7,2 ; 8,3)$ & & \\
\hline \multirow{4}{*}{ Controle } & EXP_PEC_Pré & 23 & $15,0 \pm 2,1$ & $(14,2 ; 15,8)$ & \multirow{2}{*}{$-0,219$} & \multirow{2}{*}{0,829} \\
\hline & EXP_PEC_Pós ${ }^{B}$ & 23 & $15,1 \pm 2,1$ & $(14,2 ; 15,9)$ & & \\
\hline & PEC (TOTAL)_Pré & 23 & $30,4 \pm 3,6$ & $(29,0 ; 31,9)$ & \multirow{2}{*}{$-0,084$} & \multirow{2}{*}{0,934} \\
\hline & PEC (TOTAL) Pósh & 23 & $30,5 \pm 3,7$ & $(29,0 ; 32,0)$ & & \\
\hline
\end{tabular}

a Comp_PEC_pré - Comportamentos Emocionais_Perceção Emocional Correta_Pré teste ${ }^{-}$Situações_PEC_pré - Situações Emocionais_Perceção Emocional Correta_Pré teste 'EXP_PEC_pré - Expressões Faciais_Perceção Emocional Correta_Pré teste ¿ PEC (TOTALL)_Pré -Perceção Emocional Correta Total_Pré teste

${ }^{e}$ Comp PEC pós - Comportamentos Emocionais Perceção Emocional Correta Pós teste ' Situaçõ̃es_PEC_pós - Situações Emocionais_Perceção Emocional Correta_Pós teste ${ }^{g}$ EXP PEC pós - Expressões Faciais Perceção Emocional Correta Pós teste

${ }^{n}$ PEC (TOTAL)_Pós -Perceção Emocional Correta Total_Pós teste

Na Tabela 4 observa-se claramente as diferenças que ocorreram no pré e pós teste, ou seja, após a aplicação do Programa, em ambos os grupo (experimental e controle) os resultados acerca do conhecimento emocional das crianças são diferentes para melhor ( $\mathrm{p}<0,05$ no grupo experimental), sugerindo que é importante haver este tipo de intervenção de âmbito educativo-emocional em contexto pré-escolar.

Procura-se agora identificar se, em cada momento, existem diferenças significativas entre as crianças de acordo com os níveis de escolaridade dos progenitores, uma vez que é reconhecida a importância do envolvimento familiar no desenvolvimento do conhecimento emocional das crianças. Os resultados apresentados na Figura 2 mostram, curiosamente, que quando o nível de escolaridade da mãe é mais alto há um melhor conhecimento emocional, nas três dimensões avaliadas, por parte das crianças, quer do gênero feminino, quer do gênero masculino. 

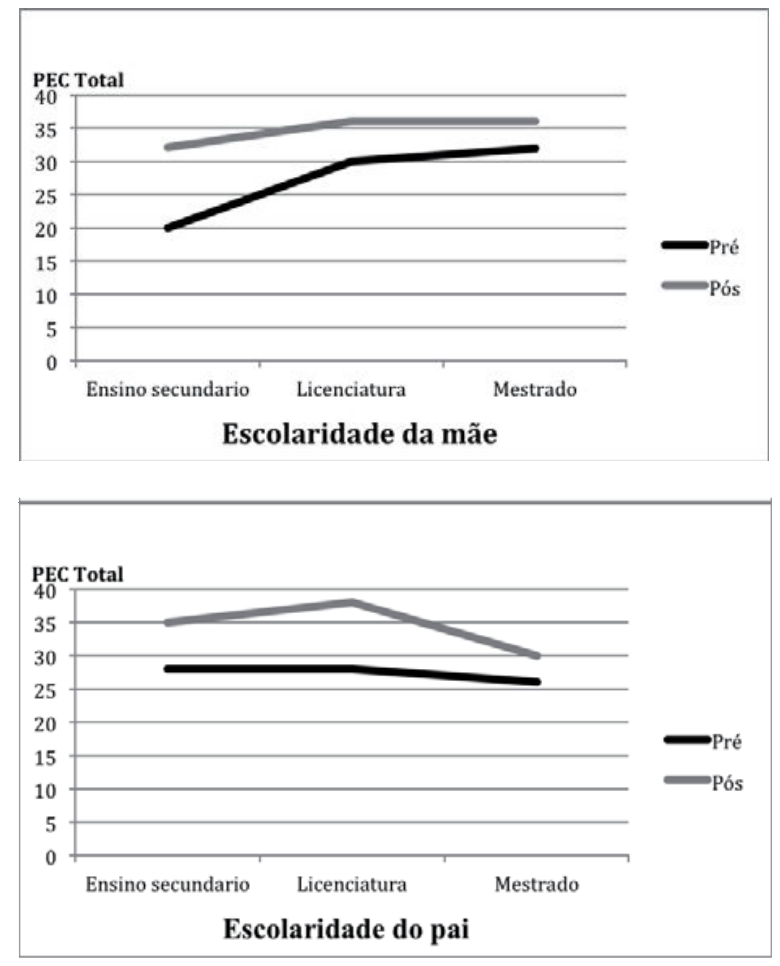

Figura 2. Resultados Obtidos no Pré e no Pós-Teste Segundo a Escolaridade da Mãe e do Pai

\section{Discussão}

Do conjunto das 25 crianças, na dimensão Comportamentos Emocionais, três delas registram uma pontuação inferior no segundo momento de avaliação, e nos resultados de duas crianças a pontuação obtida não sofreu alterações. As restantes 20 crianças registram uma melhoria na pontuação, que tendencialmente foi maior entre as crianças com pontuação inicial mais baixa.

Relativamente à dimensão Situações Emocionais duas crianças registram pontuação inferior na segunda avaliação, e uma criança manteve a pontuação entre os dois momentos de avaliação. As restantes 22 crianças evoluíram nesta dimensão, sendo também registrada uma melhoria, (embora em menor grau) entre os alunos com pontuações superiores no primeiro momento.

A dimensão Expressões Faciais foi a que obteve uma evolução mais positiva. Numa escala que poderia atingir a pontuação 20, todas as crianças obtiveram um valor de 16 ou mais no segundo momento, embora inicialmente algumas crianças se situassem no centro da escala (10), de fato foram essas crianças as que registraram maior diferença entre os dois momentos da avaliação. Todas as crianças melhoraram nesta dimensão, com exceção de quatro que mantiveram a mesma pontuação.
Em síntese, observa-se que, em todas as dimensões do conhecimento emocional, os resultados são positivos e as melhorias significativas. Os resultados sugerem que neste grupo de crianças, após a aplicação do programa de intervenção sobre o conhecimento emocional, as crianças conseguiram - com maior probabilidade de sucesso - identificar, reconhecer e nomear expressões emocionais. Deve-se registrar que não parece ter havido qualquer efeito de aprendizagem do pré para o pós teste, uma vez que, como se observa pela Tabela 4, muito provavelmente, o efeito deve-se à intervenção e não ao aprendizado. O grupo controle não apresentou variação significativa na pontuação pré e pós-teste.

A aplicação de programas que visem a promoção do conhecimento emocional promove necessariamente competências essenciais, como a empatia, o comportamento pró-social e a resolução de problemas, e surge como um dos principais preditores da competência acadêmica e do comportamento social (Fine, Izard, Mostow, Trentacosta, \& Ackermanet, 2003; Izard et al., 2001). Ao estimular o conhecimento emocional, as crianças parecem ficar mais seguras, mais autônomas, menos ansiosas e mais motivadas para a transição. Verificou-se ainda que as crianças obtiveram um desempenho mais elevado na identificação de expressões faciais tanto no pré-teste como no pós-teste. De acordo com a investigação existente, a criança, muito precocemente, adquire o conhecimento das expressões faciais (Garner, 1999), sendo capaz de reconhecê-las e nomear. No entanto, é necessário realçar que nas outras duas dimensões os resultados foram mais significativos.

Os resultados obtidos são consonantes com os marcos desenvolvimentais descritos na literatura, sendo que o conhecimento das emoções básicas é adquirido cerca dos três anos de idade. Durante a idade pré-escolar, a criança torna-se progressivamente mais eficaz na identificação, regulação e manipulação das emoções (Abe \& Izard, 1999; Alves, 2006; Melo 2005).

\section{Conclusões}

Uma das sugestões de futuro trabalho, que resultam deste estudo, prende-se com o fato de ser importante acrescentar ao PDCE (Programa de Desenvolvimento do Conhecimento Emocional) uma sessão que fomente mais especificamente a transição para o $1^{\circ} \mathrm{CEB}$ (Ciclo Ensino Básico, equivalente a quatro anos de escolaridade), por exemplo, uma visita à sala do $1^{\circ}$ ano $1^{\circ} \mathrm{CEB}$, em que as crianças do pré-escolar dialogassem com as crianças que já estão no $1^{\circ}$ ano e explorassem com a ajuda de um adulto, como elas se sentiram e viveram a transição de ciclo. Não nos parece que esta ausência tenha afetado os resultados, apenas surge como reflexão e análise dos próprios resultados. No trabalho diário de sala seria também interessante saber o que as crianças retiveram da visita e o que sentiram. Analogamente, poderíamos realizar uma última sessão sintetizadora do conteúdo das emoções, de modo a consolidar os conhecimentos adquiridos e ajudar a ajustá-los cognitivamente e emocionalmente. Identicamente poderíamos retirar a emoção normal à EACE, uma vez que parece-nos que esta não é adequada para esta faixa etária, por ser muito 
ambígua, o que confundiu as crianças. É igualmente relevante salientar que o programa aplicado precisa de ser validado junto de vários grupos-alvo, de forma a averiguarmos de fato a sua eficácia.

\section{Referências}

Abe, J., \& Izard, C. (1999). A longitudinal study of emotion expression and personality development. Journal of personality and social psychology, 77(3), 566-577. doi: 10.1037/0022-3514.77.3.566

Ackerman, B., \& Izard, C. (2004). Emotion cognition in children and adolescents: Introduction to the special issue. Journal of Experimental Child Psychology, 89(4), 271-275. doi: 10.1016/j.jecp.2004.08.003

Alves, D. (2006). O emocional e o social na idade escolar - uma abordagem dos preditores da aceitação pelos pares (Tese de Mestrado). Universidade do Porto - Faculdade de Psicologia e Ciências da Educação. Recuperado de http://hdl.handle.net/10216/19962

Alves, D., Cruz, O., Duarte, C., \& Martins, R. (2008). Escala de avaliação do conhecimento emocional (EACE) (Documento não publicado). Faculdade de Psicologia e de Ciências da Educação da Universidade do Porto. Recuperado de http://repositorio.ismt.pt/bitstream/123456789/137/1/ Disserta\%C3\%A7\%C3\%A3o\%20de\%20Mestrado.pdf

Bisquerra, R. (2000). Educación emocional y bienestar. Barcelona: Ciss Praxis.

Bonhert, A., Crnic, K., \& Lim, K. (2003). Emotional competence and aggressive behaviour in school-age children. Journal of Abnormal Child Psychology, 31(1), 79-91.

Denham, A., McKinley, M., Couchoud, E., \& Holt, R. (1990). Emotional and behavioral predictors of preschool peer ratings. Child Development, 61(4), 1145-1152. doi: 10.1111/j.1467-8624.1990.tb02848.x

Denham, S., Blair, K., DeMulder, E., Levitas, J., Sawyer, K., Auerbach-Major, S., \& Queenan (2003). Preschool emotional competence: Pathway to social competence? Child Developmental, 74(1), 238-256. doi: 10.1111/14678624.00533

Fine, S., Izard, C., Mostow, A., Trentacosta, C., \& Ackerman, B. (2003). First grade emotion knowledge as a predictor of fifth grade self-reported internalizing behaviors in children from economically disadvantaged families. Development and Psychopathology, 15, 331-342.

Garner, P. (1999). Continuity in emotion knowledge from preschool to middlechildhood and relation to emotion socialization. Motivation and Emotion, 23(4), 247-266. doi: 10.1023/A:1021386725399

Goleman, D. (1997). Inteligência Emocional. Lisboa: Temas e Debates.

Izard, C., \& Ackerman, B., (2004). Motivacional, organization and regulatory functions of discrete emotions. In M. Lewis \& J. M. Haviland-Jones (Orgs.), Handbook of Emotions. (2 ${ }^{\mathrm{a}}$ ed., pp. 253-264). Nova Iorque: The Guilford Press.

Izard, C., Fine, S., Schultz, D., Mostow, A., Ackerman, B., \& Youngstrom, E. (2001). Emotion knowledge as a predictor of social behavior and academic competence in children at risk. Psychological Science, 12(1), 18-23. doi: $10.1111 / 1467-9280.00304$

Izard, C., Stark, K., Trentacosta, C., \& Schultz, D. (2008). Beyond emotion regulation - emotion utilization and adaptive functioning. Child Development Perspectives, 2(3). 156-163. doi: 10.1111\%2Fj.17508606.2008.00058.x

Machado, P., Veríssimo, M., Santos, A., \& Rolão, T. (2008). Efeitos diretos e indiretos do conhecimento das emoções sobre a reputação social em crianças do pré-escolar. Estudo financiado pela F.C.T (PTDC/PSI/66172/2006) e apresentado no Instituto Superior de Psicologia Aplicada.

Mayer, J., \& Salovey, P. (1997). What is emotional intelligence? In P. Salovey \& D. J. Sluyter (Orgs), Emotional development and emotional intelligence: educational implications. Nova Iorque: Basics Books.
Melo, A. (2005). Emoções no periodo escolar: Estratégias parentais face à expressão emocional e sintomas de internalização e externalização da criança (Tese de Mestrado). Universidade do Minho. Recuperado de http://hdl.handle. net/1822/4926

Mostow, A., Izard, C., Fine, S., \& Trentacosta, C. (2002). Modeling emotional, cognitive, and behavioral predictors of peer acceptance. Child Development, 73(6), 1775-1787. doi: 10.1111\%2f1467-8624.00505

Pereira C., \& Soares L. (2011). Programa de desenvolvimento do conhecimento emocional (Documento não publicado). Universidade da Madeira.

Rodrigues, M. (2005). Do jardim de infância à escola: Estudo longitudinal duma coorte de alunos. Interacções, 1(1), 7-24.

Saarni, C. (1997). Coping with aversive feelings. Motivation and Emotion, 21(1), 45-63.

Saarni, C. (1999). The development of emotional competence. The Guidford series on social and emotional development. Nova Iorque: The Guildford Press.

Schultz, D., Izard, C., \& Bear, G. (2002). Children's emotion processing: The development of the Assessment of Children's Emotion Skills (ACES). Manuscript under review

Vallés, A., \& Vallés, C. (2000). Inteligencia emocional: Aplicaciones educativas. Madrid: Editorial EOS. 
Carla Pereira, Mestrado em Psicologia da Educação pela Universidade da Madeira, é educadora de Infância na Secretaria Regional da Educação e Recursos Humanos. Endereço para correspondência: Caminho da Achada $n^{\circ} 24$ Edifício Jardins da Achada Bloco 2 R/C AE 9000-208 Funchal, 962569530. E-mail: carlapereira@netmadeira.com

Luísa Soares, Doutora em Psicologia pela Universidade Ramon Llull em Barcelona - Espanha, é Professora Auxiliar no M-iti Madeira Interactive Technologies Institute na Universidade da Madeira - Portugal. E-mail: 1soares@uma.pt

Diana Alves, Doutora em Psicologia pela Universidade do Porto, é Assistente Convidada na Faculdade de Psicologia e de Ciências da Educação da Universidade do Porto (FPCEUP). E-mail: dianalves@fpce.up.pt

Orlanda Cruz, Doutora em Psicologia pela Universidade do Porto, é Professora Associada na Faculdade de Psicologia e de Ciências da Educação da Universidade do Porto (FPCEUP) E-mail: orlanda@fpce.up.pt

Mónica Fernandez, Licenciatura em Matemática-Estatística pela Universidade da Madeira, é Analista de dados e Consultora autônoma. E-mail: cruz.monica.fernandez@gmail.com 